\title{
PROBLEMS AND EFFECTS OF A TSUNAMI INUNDATION FORECAST SYSTEM DURING THE 2011 TOHOKU EARTHQUAKE
}

\author{
Ikuo $\mathrm{ABE}^{1}$ and Fumihiko IMAMURA ${ }^{2}$ \\ ${ }^{1}$ Member of JSCE, Associate Professor, Dept. of Social Environment, Tokoha University \\ (Obuchi 325, Fuji, Shizuoka 417-0801, Japan) \\ E-mail: i-abe@fj.tokoha-u.ac.jp \\ ${ }^{2}$ Member of JSCE, Professor, IRIDeS, Tohoku University (6-6-11-1106, Aoba, Sendai 980-8579, Japan) \\ E-mail: imamura@irides.tohoku.ac.jp
}

\begin{abstract}
Before the occurrence of the 2011 Tohoku earthquake, a tsunami inundation forecast system and a GPS buoy were installed in Tohoku. The huge tsunami generated by the 2011 Tohoku earthquake was observed with the GPS buoy, and the data were used to revise the tsunami warning. However, the tsunami inundation forecast system was not able to help in the evacuation. The tsunami inundation forecast system was a system that displayed an inundation forecast map corresponding to the tsunami height observed in the GPS buoy in real-time. We thought that the damage would have been mitigated if the information from these systems were used for evacuation. Especially, the tsunami reached Sendai around 36 minutes after the tsunami was observed in the Kesennuma-oki GPS buoy. We thought that damage might have been mitigated if the information was conveyed during these 36 minutes. The 2011 Tohoku earthquake was generated in Tohoku where such a system was constructed. Therefore we thought that we must report the process of constructing these systems, the effects of the systems and the problems encountered.
\end{abstract}

Key Words : 2011 Tohoku earthquake, tsunami inundation, forecast system, real-time

\section{INTRODUCTION}

The 2011 Tohoku earthquake occurred on March 11 , and many people died as a result of the huge tsunami with a height of more than $20 \mathrm{~m}$. In the Tohoku district that suffered the most damage, the occurrence of the Miyagi-oki earthquake caused great anxiety. Thus mitigation measures for an earthquake and tsunami were carried out. One of the measures was the construction of a tsunami observation system by a GPS buoy. The tsunami inundation forecast system was another measure. These systems were constructed for a huge tsunami disaster.

The system was constructed due to problems with the tsunami warning system of the Japan Meteorological Agency. The tsunami warning system operated by the Japan Meteorological Agency estimates a tsunami warning based on seismic information. This system was constructed through a tsunami simulation that assumed a seismic condition beforehand. Therefore, in cases of a tsunami earthquake and a landslide of the sea bottom, there was fear that a tsunami warning announcement would be underes- timated. The reason was that the magnitude of the earthquake would be estimated to be small when a tsunami earthquake was generated.

The 2011 Tohoku earthquake was not a tsunami earthquake, but the first warning estimated a tsunami over $3 \mathrm{~m}$, which was much smaller than the tsunami that was actually generated. Therefore we considered the effects of, and the problems with these systems.

\section{ASSUMPTION OF AN EARTHQUAKE AND A TSUNAMI}

The Tohoku district had been hit by big earthquakes in the past. The Meiji Sanriku earthquake in 1896 generated a huge tsunami that went up to $38 \mathrm{~m}$ and more than 20,000 people died. The Showa Sanriku earthquake in 1933 generated a huge tsunami and more than 3,000 people died. The place where earthquakes occurred repeatedly was known as Miyagi-oki. Here, an earthquake of magnitude around 7.5 occurred roughly every 37 years on the 
average. And, at a place that was nearer to the Japan Trench than this place, the seismic area that generated a tsunami in 1793 and 1897 was identified. The locations of these earthquakes are shown in Fig.1. The probability of an earthquake with a magnitude of around 7.5 occurring more than $99 \%$ within 30 years was published in these areas by statistical technique. When this earthquake connected with the seismic area close to the Japan Trench, it was estimated that the magnitude would become 8.0. In Miyagi and Iwate, many people prepared measures for this earthquake. Fig.2 shows a tsunami inundation map of Sendai that assumed the Miyagi-oki earthquake (magnitude 8.0). This inundation map was made by the Miyagi Prefectural Government ${ }^{1}$. In Fig.2, the inundation area is shown in green. This area shows some degree of inundation by the Miyagi-oki earthquake of magnitude 8.0. Thus, the Arahama Elementary School was selected as a shelter. However, in the area shown in Fig.2, the tsunami of the 2011 Tohoku earthquake went far beyond the assumption, and the tsunami arrived at the area near the expressway.

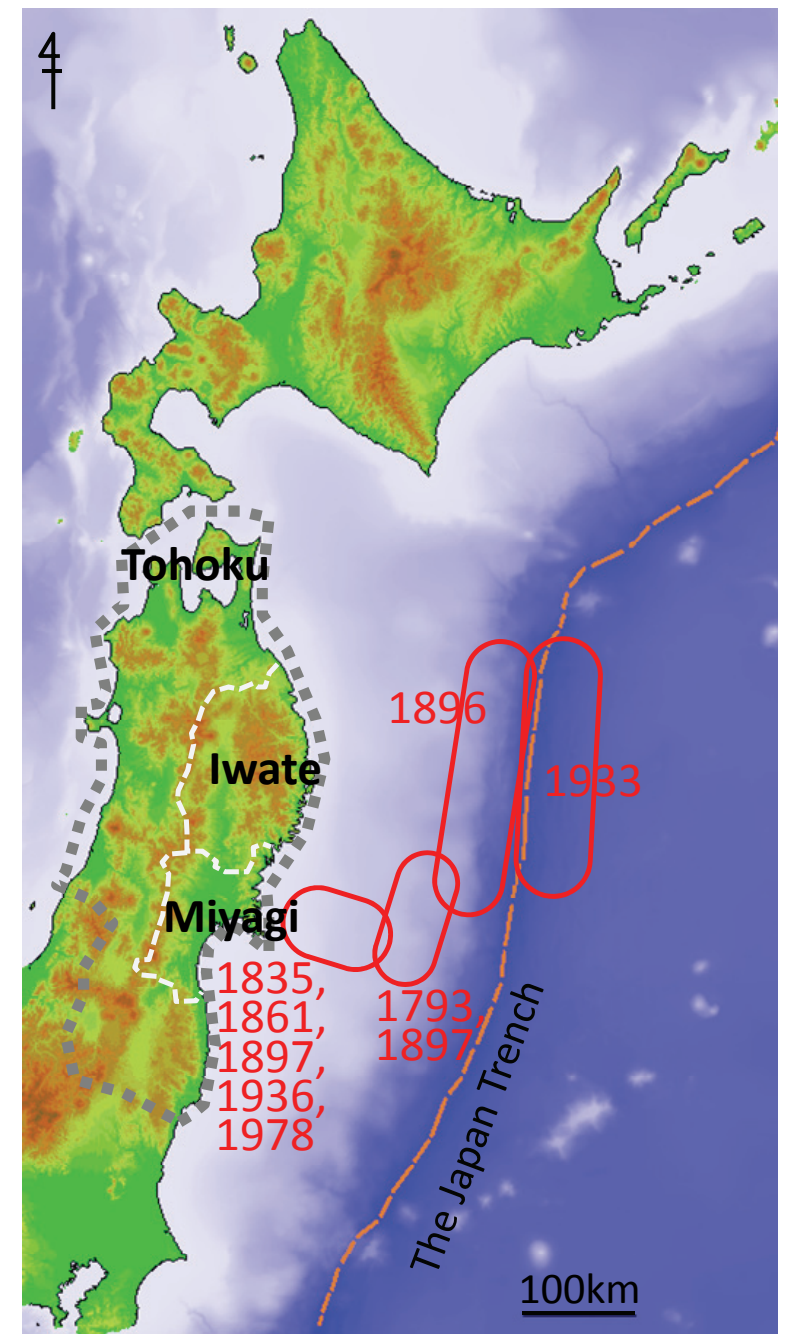

Fig.1 Location of major earthquakes around Tohoku.

\section{CONSTRUCTION OF GPS BUOY AND TSUNAMI INUNDATION FORECAST SYSTEM}

The construction of the GPS buoy system was started in 2007. A place to install a GPS buoy was investigated first. Like the 1896 Meiji Sanriku and 1933 Showa Sanriku, the tsunami simulation that supposed that many earthquakes were generated along the Japan Trench was carried out. In this investigation, we simulated the tsunami arrival times from various tsunami sources and they are shown in Fig.3. As a result, the GPS buoy was installed where we could confirm the scale of the tsunami in at least two places. This was to keep the reliability of the system for disaster mitigation. The reliability of the observation data increases by confirming the scale of the tsunami in two places. It is also thought that the fault tolerance of the system increases.

The first plan for the setting of the GPS buoy is shown in Fig.4. In addition, the effect of the GPS buoy is shown as a scenario of time required for the first mitigation action when this plan was made.

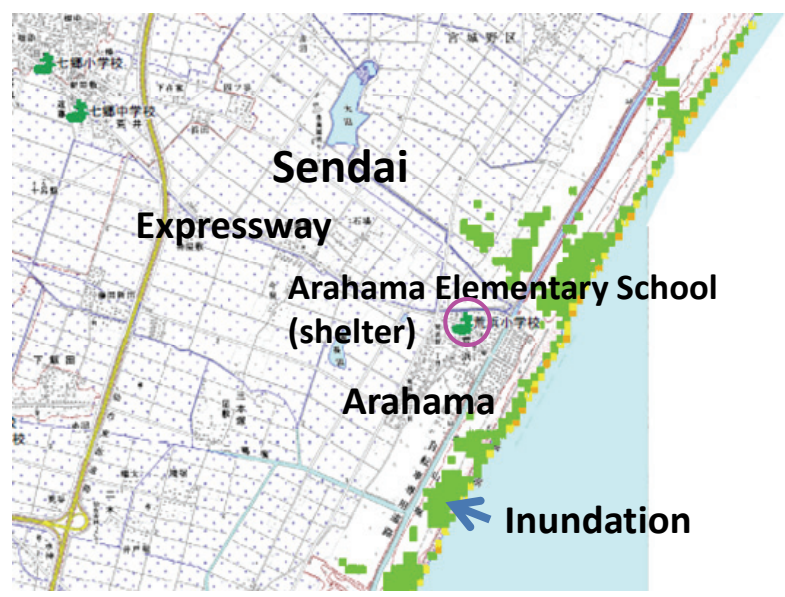

Fig.2 Tsunami inundation map of Sendai.

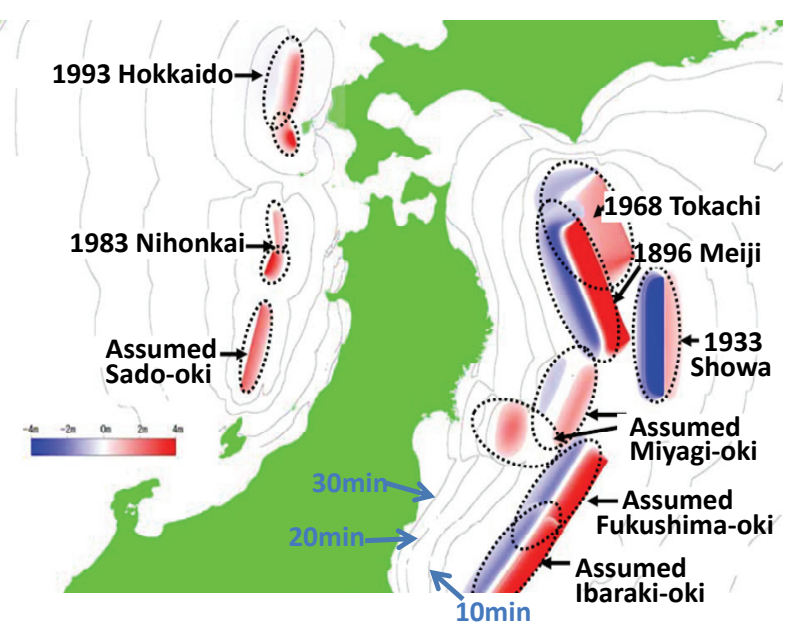

Fig.3 Tsunami arrival times from various tsunami sources. 
The scenario that assumes the 1896 Meiji Sanriku is shown in Table 1. This scenario assumes that the GPS buoy is located in the $20 \mathrm{~km}$ offing.

The setting was coordinated with the fishery right and the topography situation of the sea bottom, and the final setting place was an offing of $11-16 \mathrm{~km}$. The GPS buoy was installed based on this plan and setting it on the Pacific side of the Tohoku district was completed in 2009. The final plan is shown in Fig.4.

The tsunami inundation forecast system was developed after the installation of the GPS buoy. This system was developed using the Digital Japan Web System ${ }^{2)}$, and can be operated using a web browser.

When we operated this system, we chose the tsunami height at a GPS buoy or the seismic center information from a menu, and the inundation forecast range is displayed in Fig.5. In this system, the tsunami inundation area was simulated beforehand, and the data were saved in a database. After an earthquake occurs, the tsunami may arrive some time later. Therefore it is effective as a database system.
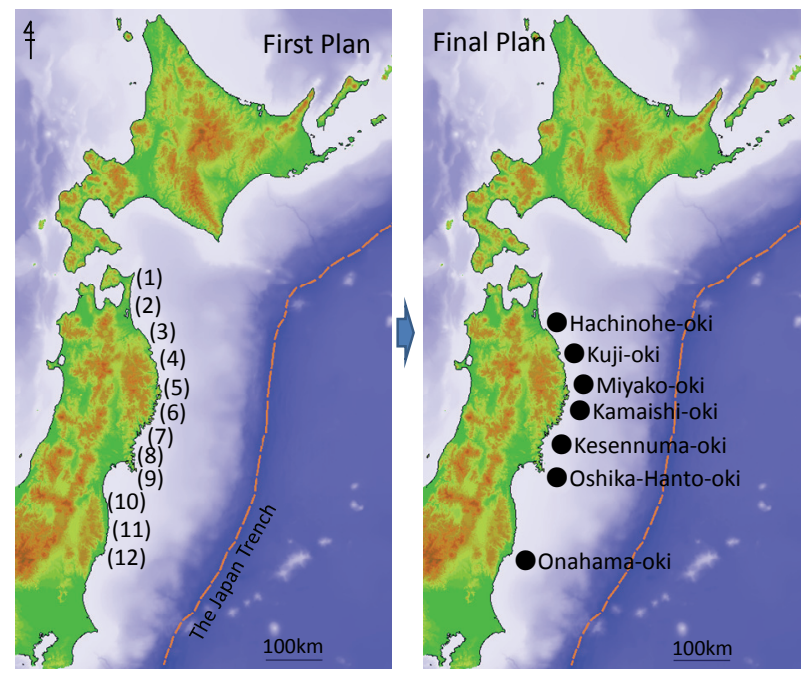

Fig.4 Plan for setting the GPS buoy.

Table 1 The scenario that assumes the 1896 Meiji Sanriku.

\begin{tabular}{|c|l|}
\hline $\begin{array}{c}\text { Elapsed time after } \\
\text { the earthquake } \\
\text { occurrence }\end{array}$ & \multicolumn{1}{|c|}{ Scenario } \\
\hline $28 \mathrm{~min}$ & $\begin{array}{l}\text { (5)Miyako-oki; Peak arrival of the } \\
\text { first wave(3.6m) }\end{array}$ \\
\hline $29 \mathrm{~min}$ & $\begin{array}{l}\text { (6)Kamaishi-oki; Peak arrival of the } \\
\text { first wave(1.6m) }\end{array}$ \\
\hline $31 \mathrm{~min}$ & $\begin{array}{l}\text { (5)Miyako-oki; Peak arrival of the } \\
\text { first wave(0.4m) }\end{array}$ \\
\hline $40 \mathrm{~min}$ & $\begin{array}{l}\text { The peak of the first wave arrives at } \\
\text { Omoto of Iwate (15.2m). }\end{array}$ \\
\hline $47 \mathrm{~min}$ & $\begin{array}{l}\text { The peak of the first wave arrives at } \\
\text { Miyako (10.0m) }\end{array}$ \\
\hline $51 \mathrm{~min}$ & $\begin{array}{l}\text { The peak of the first wave arrives at } \\
\text { Kamaishi (6.6m) }\end{array}$ \\
\hline
\end{tabular}

The tsunami simulation conditions when the database was built are shown in Table 2. Furthermore, it was hoped that a function shown next was necessary for this system because this system was a system for a disaster.

1) In case of a blackout, a local government staff can operate this system for a few hours.

2) The tsunami forecast and the tsunami observation information are updated automatically.

3) When the Internet is blocked, this system becomes available.

These functions were not realized because of insufficient development resources for the tsunami inundation forecast. However, a system trial was done in July 2010 in the cities of Miyako, Kamaishi, Ofunato, and Kesennuma.

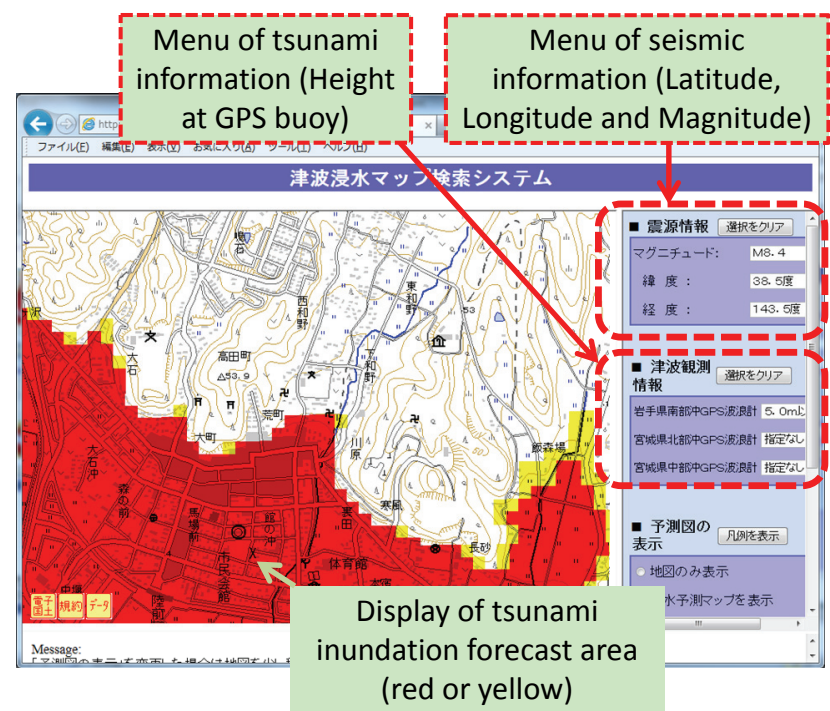

Fig.5 Display of the tsunami inundation forecast system.

Table 2 Conditions of the tsunami simulation when the database was built ${ }^{3)}$.

\begin{tabular}{|l|l|}
\hline \multicolumn{1}{|c|}{ Items } & \multicolumn{1}{|c|}{ Contents } \\
\hline Location of fault & $\begin{array}{l}\text { Around 1896 Meiji Sanriku and assumed } \\
\text { Miyagi-oki earthquake (0.5 degrees in- } \\
\text { terval at latitude and longitude). }\end{array}$ \\
\hline $\begin{array}{l}\text { Length and } \\
\text { Width }\end{array}$ & $\begin{array}{l}\text { Setting by scaling raw. } \\
\text { But the magnitude was fixed, and the ratio } \\
\text { of the width was coordinated with length } \\
\text { by 3 patterns (One to two, one to three and } \\
\text { one to four). }\end{array}$ \\
\hline Magnitude & $7.6,7.8,8.0,8.2$ and 8.4 \\
\hline Strike & $\begin{array}{l}\text { Setting along the Japan Trench (180 and } \\
195 \text { degrees). }\end{array}$ \\
\hline Depth & 1 and 10km \\
\hline Dip angle & 20 and 45 degrees \\
\hline Slip angle & 90 degrees \\
\hline Dislocation & Setting by scaling raw. \\
\hline $\begin{array}{l}\text { Number of the } \\
\text { conditions }\end{array}$ & 3,600 \\
\hline
\end{tabular}


Furthermore, on January 20, 2011, a briefing session was held for all local government staff from Miyako City of Iwate to Soma City of Fukushima. It was only one-and-a-half months earlier than the great earthquake disaster.

\section{OCCURRENCE OF THE 2011 TOHOKU EARTHQUAKE}

A huge tsunami hit Tohoku where these systems had been constructed. The earthquake occurred at 14:46 on March 11, 2011 (JST). Seismic information and a tsunami warning were announced three minutes after the occurrence of the earthquake. At first, the announced information on the earthquake was magnitude 7.9 and the tsunami warning was more than $3 \mathrm{~m}$ (for Iwate and Miyagi). Afterwards, tsunami observation information at some places was announced by the Japan Meteorological Agency. The tsunami observation information announced by the Japan Meteorological Agency is shown in Table 3 where a GPS buoy observed the tsunami height at $6 \mathrm{~m}$ or more at 15:12, and the tsunami warning for Miyagi was revised as more than $10 \mathrm{~m}$ at 15:14.

Thus, the GPS buoy observed tsunamis of more than $6 \mathrm{~m}$ that were useful for the revision of the tsunami warning. However, the tsunami inundation forecast system was not able to help in evacuation because the server was stopped by the blackout.

Table 3 Information from the Japan Meteorological Agency4).

\begin{tabular}{|l|l|}
\hline $\begin{array}{c}\text { Time } \\
\text { (JST) }\end{array}$ & \multicolumn{1}{|c|}{ Event or Information } \\
\hline $14: 46$ & Occurennce of 2011 Tohoku earthquake \\
\hline $14: 49$ & $\begin{array}{l}\text { Tsunami warning (more than 3m for Iwate, } \\
\text { Miyagi, Fukushima), Seismic information (38.0N, } \\
142.9 E, \text { Depth=10km, Magnitude=7.9) }\end{array}$ \\
\hline $14: 50$ & $\begin{array}{l}\text { Tsunami arrival time and height; } \\
\text { Iwate (Estimation of already arrival, 3m) } \\
\text { Miyagi (15:00, 6m), Fukushima (15:10, 3m) }\end{array}$ \\
\hline $14: 59$ & $\begin{array}{l}\text { Tsunami observation; Ofunato of Iwate(First wave } \\
14: 46 /-0.2 \mathrm{~m}, \text { max wave 14:54/0.2m) }\end{array}$ \\
\hline $15: 01$ & $\begin{array}{l}\text { Tsunami observation; Kamaishi of Iwate(First } \\
\text { wave 14:45/-0.1m, max wave 14:56/0.2m) }\end{array}$ \\
\hline $15: 14$ & $\begin{array}{l}\text { Tsunami observation; } \\
\text { Kamaishi-oki GPS bouy(First wave 14:50/-0.3m) }\end{array}$ \\
\cline { 2 - 3 } & $\begin{array}{l}\text { Tsunami arrival time and height; } \\
\text { Iwate (Confirmation of tsunami arrival, 6m) } \\
\text { Miyagi (Confirmation of tsunami arrival, 10m) } \\
\text { Fukushima (Confirmation of tsunami arrival, 6m) }\end{array}$ \\
\hline 15:17 & $\begin{array}{l}\text { Tsunami observation; } \\
\text { Kamaishi-oki GPS bouy(Max wave 15:12/ 6.8m) }\end{array}$ \\
\hline $15: 25$ & $\begin{array}{l}\text { Tsunami observation; Kesennnuma-oki GPS } \\
\text { bouy(Max wave 15:14/ 6.0m) }\end{array}$ \\
\hline
\end{tabular}

Fig.6 shows a tsunami inundation forecast in Rikuzen-takata using this system. The location of Rikuzen-takata is shown in Fig.7. At 15:12, the Kamaishi-oki GPS buoy observed that the tsunami height was $6.8 \mathrm{~m}$, but this was not registered by this system. Therefore, Fig.6 shows the displayed results of a tsunami inundation forecast when the tsunami height was more than $5 \mathrm{~m}$. "More than $5 \mathrm{~m}$ " was the maximum value registered by this system, but we understand that this system displayed information similar to that in a real tsunami inundation area. In Fig.6, the red area displays an inundation forecast when a dike and a breakwater were not broken, and the yellow area displays an inundation forecast when they were broken.

The number of dead or missing people in Rikuzen-takata reached 1,773 and most of the city areas were inundated by this tsunami. The arrival time of the tsunami near the Rikuzen-takata City office was estimated around 15:285). If this system had been operated, it is thought that information as shown in Fig.6 would have been conveyed about 15 minutes before the arrival of the tsunami, and it shows that the use of the system might have mitigated damage.

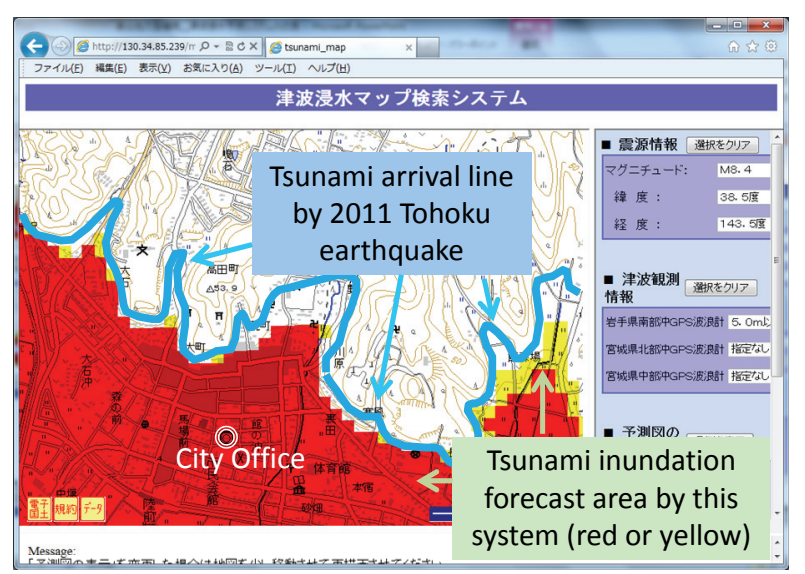

Fig.6 Tsunami inundation forecast in Rikuzen-takata.

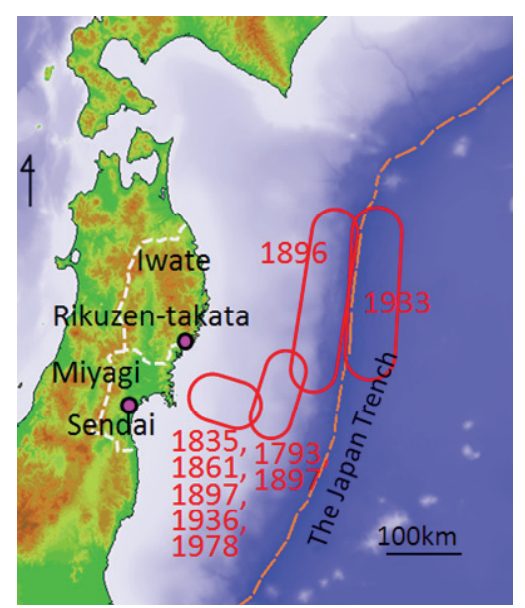

Fig.7 Locations of Rikuzen-takata and Sendai. 


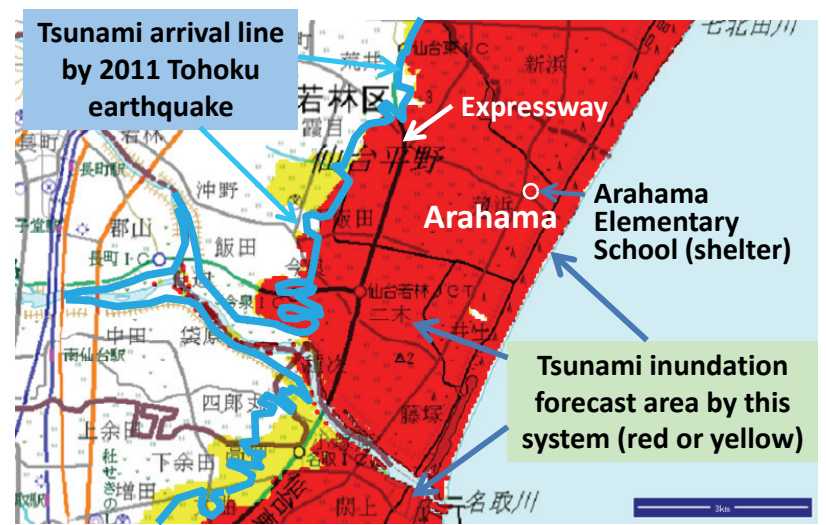

Fig.8 Tsunami inundation forecast in Sendai.

Furthermore, a tsunami inundation forecast map in Sendai is shown in Fig.8. The location of Sendai is shown in Fig.7. Fig.8 shows a tsunami inundation forecast corresponding to the tsunami observation data of the Kesennuma-oki GPS buoy. At the GPS buoy of the Kesennuma-oki, a tsunami more than $6 \mathrm{~m}$ was observed at 15:14. The tsunami arrived at Sendai at around 15:50, and dead or missing people were more than 900. Fig.8 is an area including Arahama that is shown in Fig.2. Before the 2011 Tohoku earthquake, measures such as disaster mitigation drills were carried out for the Miyagi-oki earthquake (magnitude 8.0). In the case of the 2011 Tohoku earthquake, this system showed that the inundation area was wider than the assumption. If this information was conveyed when the tsunami was observed in the GPS buoy, many people could have evacuated to safe places and the damage might have been mitigated.

\section{CONCLUSION}

We were able to get some results in the case of the 2011 Tohoku earthquake. One is that the tsunami observation in the offing is useful for revising the tsunami warning. Another one is that a tsunami inundation forecast corresponding to the tsunami ob- servation is useful for evacuation. Furthermore, we were able to know the problems of the system. When the system of the tsunami inundation forecast was developed, there were several demands such as automation. However, we experienced a huge tsunami disaster without being able to secure a budget to adequately satisfy those demands. Huge disasters rarely occur but they cause big damage. To prepare for a future huge disaster, it is very important that appropriate investment be made to mitigate its risks. Additionally, it is important that advanced information be conveyed when an earthquake and a tsunami are generated, and this information must be coupled with the necessary action for disaster mitigation. Finally, to develop a disaster mitigation system for such a huge disaster, we must improve the methods for estimating its risks and mitigation effects.

ACKNOWLEDGMENT: This system was developed in cooperation with the Ministry of Land, Infrastructure and Transport. We also received technical advice from a committee.

\section{REFERENCES}

1) Miyagi Prefectural Government: The third estimation for Miyagi-oki earthquake, http://www.pref.miyagi.jp/soshiki/ kikitaisaku/ks-sanzihigai-sinsuiyosokumap-top.html, 2012 (in Japanese).

2) Geospatial Information Authority of Japan: Digital Japan Portal Web Site, http://portal.cyberjapan.jp/index.html, 2012 (in Japanese).

3) Abe, I. and Imamura, F.: Verification of the Real-time Forecasting system for Tsunami Inundation using the GPS Buoy in the Case of the 2011 Tohoku Earthquake, Journal of Japan Society of Civil Engineers, Ser. B2 (Coastal Engineering), Vol. 68, 2012 (in Japanese).

4) Japan Meteorological Agency: Tsunami Warnings/ Advisories, http://www.jma.go.jp/en/tsunami/, 2011.

5) Ushiyama, M. and Yokomaku, S.: Estimation of situation in Rikuzentakata city just before tsunami attack based on time stamp data, Japan Society for Natural Disaster Science, Vol. 31-1, pp. 47-58, 2012 (in Japanese).

(Received April 3, 2013) 